\title{
Hypopharynx in termites: Morphological and functional aspects
}

\author{
Iago Bueno da Silva, Ana Maria Costa-Leonardo* \\ Laboratório de Cupins, Departamento de Biologia, Instituto de Biociências, UNESP - Univ Estadual Paulista, Av. 24A, No. 1515, 13506-900 Rio Claro, SP, Brazil
}

\section{A R T I C L E I N F O}

\section{Keywords:}

Mouthpart

Scanning microscopy

Sensilla

Isoptera

\begin{abstract}
A B S T R A C T
The hypopharynx morphology in workers, pseudergates, and soldiers was described in six families of Isoptera using scanning electronic microscopy. This is the first comparative study to detail the hypopharynx among different species of termites, and included 4 one-piece type (OP) and 9 multiple-pieces type termites (MP). The results showed different arrangements of the hypopharynx trichomes, with fewer of these structures in the frontal region of the hypopharynx in pseudergates and soldiers of OP termites. These characteristics did not apply to Serritermes serrifer, since its pseudergates displayed a large quantity of trichomes on the frontal surface. This species may not resemble other OP termites because it does not live inside a piece of wood, but rather are inquilines inside Cornitermes spp. nests. Similar morphology of this mouthpart was observed in the different species of MP termites, with workers exhibiting many unidirectional trichomes on the frontal surface and soldiers presenting fewer of these trichomes. The morphology of the hypopharynx seems to reflect the lifestyle of these species, because MP termites are able to exploit external water sources. Since different arrangements of hypopharynx trichomes are used for water intake via capillary action, the present data reinforce the soldiers' dependence on workers to obtain water and food through the process of trophallaxis. Three different types of sensilla were observed on the lateral region of the hypopharynx: chaetica, basiconica and campaniformia. Chaetica act as chemoreceptors, while basiconica and campaniformia are mechanoreceptors, used in feeding and environmental perception. Better understanding of hypopharynx morphology permits the inference of ecological habits among OP and MP termites, and reflects the physiological differences between workers and soldiers.
\end{abstract}

\section{Introduction}

Termites may be classified into two groups according to their ecology and feeding habits: one-piece type termites (OP), which have nests inside food sources, and multiple-pieces type termites (MP), which have nests separate from food and water sources (MP) (Korb, 2008). Moisture plays an important role in the life of termites, particularly in the MP group, since water is essential for nest maintenance and construction, feeding of dependent castes, and physiological functions (Pearce, 1997). The water used by termites may come from different sources such as the metabolic breakdown of food or may be directly acquired from moist soil (Silveira-Neto et al., 1976; Pearce, 1997).

The hypopharynx is a mouthpart comprised of a thin lobe similar to a tongue, which is coated with different sclerotized plates and connected to the insect head between the mouth and the labrum (Snodgrass, 1993; Buder and Klass, 2013). In general, insect mouthparts are used in the handling and processing of food, but termites sometimes use these structures, including the hypopharynx, during tunnel excavation (Li and Su, 2009; Chapman et al., 2013).
A previous study also demonstrated that termites use the hypopharynx during the process of water intake, protruding and pressing this structure toward a water source (Sieber and Leuthold, 1981). The hypopharynx of Macrotermes workers is covered with unidirectional trichomes that are responsible for capillary forces which assist in water intake (Sieber and Kokwaro, 1982; Lys and Leuthold, 1994).

A recent work of Buder and Klass (2013) compared the hypopharynx morphology of Dictyoptera in 7 cockroaches, 1 Mantodea and in the basal termite Mastotermes darwiniensis under stereomicroscopy. The authors provided adequate terminology of the different parts and correspondent musculature of the hypopharynx, but detailed morphology of the trichomes, sensilla and cuticle ornamentations remains poorly known in the relevant literature.

Studies of the hypopharynx in Isoptera are scarce and a comparative analysis of this structure among termites has not been conducted to date. This present study consequently investigated the ultramorphology of the hypopharynx and its trichomes in different species of OP and MP termites to clarify correlations between these structures and different ecological habits. Basic knowledge of hypopharynx morphology is also important for inferring function and provides information for

\footnotetext{
* Corresponding author.

E-mail address: amcl@rc.unesp.br (A.M. Costa-Leonardo).
} 
Table 1

Characteristics and distribution of trichomes and sensilla in the hypopharynx of the different species studied.

\begin{tabular}{|c|c|c|c|c|c|}
\hline & Species & Caste & Dorsal region & Frontal region & Sensilla \\
\hline \multirow[t]{8}{*}{ OP termites } & Cryptotermes brevis & $\mathrm{p}$ & many thick trichomes with regular distribution & few thick trichomes & basiconica/campaniformia \\
\hline & & $\mathrm{s}$ & many thick trichomes with regular distribution & few thick trichomes & basiconica/campaniformia \\
\hline & Kalotermes flavicollis & $\mathrm{p}$ & thick trichomes with irregular distribution & few thick trichomes & basiconica/chaetica/campaniformia \\
\hline & & s & mostly surface without trichomes & few thick trichomes & basiconica/chaetica/campaniformia \\
\hline & Porotermes quadricollis & $\mathrm{p}$ & many thick trichomes with regular distribution & few thick trichomes & basiconica/chaetica \\
\hline & & s & many thick trichomes with regular distribution & few thick trichomes & campaniformia/chaetica \\
\hline & Serritermes serrifer & $\mathrm{p}$ & mostly surface without trichomes & many thin trichomes & basiconica/chaetica \\
\hline & & $\mathrm{s}$ & mostly surface without trichomes & very few thin trichomes & basiconica/chaetica \\
\hline \multirow[t]{18}{*}{ MP termites } & Mastotermes darwiniensis & $\mathrm{w}$ & mostly surface without trichomes & many thin trichomes & basiconica/chaetica \\
\hline & & $\mathrm{s}$ & mostly surface without trichomes & few thin trichomes & basiconica/chaetica \\
\hline & Coptotermes gestroi & $\mathrm{w}$ & thin trichomes with irregular distribution & many thin trichomes & basiconica/chaetica/campaniformia \\
\hline & & s & very few thin trichomes & very few thin trichomes & basiconica/chaetica \\
\hline & Heterotermes tenuis & $\mathrm{w}$ & thin trichomes with irregular distribution & many thin trichomes & basiconica/chaetica \\
\hline & & s & very few thin trichomes & very few thin trichomes & basiconica/chaetica \\
\hline & Syntermes grandis & Dw & mostly surface without trichomes & many thin trichomes & basiconica/chaetica/campaniformia \\
\hline & & Ww & mostly surface without trichomes & many thin trichomes & basiconica/chaetica/campaniformia \\
\hline & & $\mathrm{s}$ & mostly surface without trichomes & very few thin trichomes & basiconica/chaetica/campaniformia \\
\hline & Cornitermes cumulans & $\mathrm{w}$ & thin trichomes with irregular distribution & many thin trichomes & basiconica/chaetica \\
\hline & & $\mathrm{s}$ & thin trichomes with irregular distribution & very few thin trichomes & basiconica/chaetica \\
\hline & Nasutitermes aquilinus & $\mathrm{Mw}$ & thin trichomes with irregular distribution & many thin trichomes & basiconica/chaetica \\
\hline & & $\mathrm{mw}$ & thin trichomes with irregular distribution & many thin trichomes & basiconica/chaetica \\
\hline & & Ms & very few thin trichomes & very few thin trichomes & basiconica/chaetica/campaniformia \\
\hline & & $\mathrm{ms}$ & very few thin trichomes & very few thin trichomes & basiconica/chaetica/campaniformia \\
\hline & Ruptitermes reconditus & $\mathrm{w}$ & $\begin{array}{l}\text { thin trichomes with irregular distribution/tiling } \\
\text { ornamentations }\end{array}$ & many thin trichomes & basiconica/chaetica/campaniformia \\
\hline & Ruptitermes pitan & $\mathrm{w}$ & $\begin{array}{l}\text { thin trichomes with irregular distribution/tiling } \\
\text { ornamentations }\end{array}$ & many thin trichomes & basiconica/chaetica \\
\hline & Ruptitermes xanthochiton & $\mathrm{w}$ & $\begin{array}{l}\text { thin trichomes with irregular distribution/tiling } \\
\text { ornamentations }\end{array}$ & many thin trichomes & basiconica \\
\hline
\end{tabular}

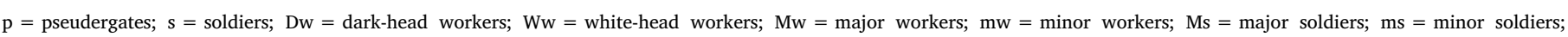
$\mathrm{w}=$ workers.

taxonomic work.

\section{Material and methods}

\subsection{Termites}

We analyzed workers or pseudergates and soldiers of 13 species belonging to six different families and a minimum of three individuals of each caste were used for this study. One-piece type termites: Cryptotermes brevis, Kalotermes flavicollis (Kalotermitidae), Porotermes quadricollis (Stolotermitidae) and Serritermes serrifer (Serritermitidae). Multiple-pieces type termites: Nasutitermes aquilinus, Syntermes grandis, Cornitermes cumulans, Ruptitermes reconditus, Ruptitermes pitan and Ruptitermes xanthochiton (Termitidae), Coptotermes gestroi, Heterotermes tenuis (Rhinotermitidae) and Mastotermes darwiniensis (Mastotermitidae). The species were obtained from natural nests located in Rio Claro, SP, Brazil or from samples kept in $80 \%$ ethanol at the termite laboratory of UNESP Rio Claro, SP, Brazil.

\subsection{Scanning electron microscopy}

Hypopharynxes of the different termites were isolated and fixed in Karnovisky fixative: $2 \%$ paraformaldehyde (Sigma-Aldrich), $2.5 \%$ glutaraldehyde (Sigma-Aldrich) in $0.1 \mathrm{M}$ sodium cacodylate buffer, $\mathrm{pH} 7.4$, for $24 \mathrm{~h}$. Next, they were dehydrated in a series of successive ethanol solutions of $70 \%, 80 \%$, and $90 \%$ each for $10 \mathrm{~min}$ and then dehydrated in baths of $100 \%$ ethanol three times, each for $10 \mathrm{~min}$. They were subjected to critical point drying (Balzers CPD 030), mounted on aluminum stubs using double-sided copper sticky tape, sputtered with gold (Balzers SCD 050), and finally documented with a Hitachi TM 3000 scanning electron microscope (Hitachi,Tokyo, Japan) operated at $15 \mathrm{kV}$.

\subsection{Hypopharynx terminology}

We used the terminology proposed by previous studies of the hypopharynx in Isoptera (Sieber and Kokwaro, 1982; Lys and Leuthold, 1994; Grube and Rudolph, 1995), including "trichomes" for the hairs which are distributed on the surface of the hypopharynx.

\section{Results}

The hypopharynxes presented different sizes, following the size variations among the different species studied. However, the shape of this mouthpart was similar, composed of a small pouch-like structure, which had an elongated base. The similarities and differences among the termite hypopharynxes are exposed in Table 1, including the location, distribution and quantification of the trichomes as well as the sensilla classification. The dorsal and frontal surfaces of the hypopharynx in each species are detailed below. The different location and morphology of the trichomes on the hypopharynx permitted differentiation between OP and MP termites, with the exception of $S$. serrifer which did not conform to the OP pattern. This structure was more uniform among the MP termites studied, although there were several differences related to the quantity and disposition of the trichomes between the worker and soldier castes (Table 1).

\subsection{Cryptotermes brevis (Kalotermitidae)}

The dorsal surface of the pseudergate hypopharynx exhibited a large quantity of trichomes; these structures were long and thick, and were arranged in a single direction towards the posterior region (Fig. 1A). Additionally, the dorsal surface was surrounded by two stripes of long, thick trichomes and the lateral cuticle, which featured scale-type ornamentations (Fig. 1A). The frontal surface exhibited a small quantity of long, thick trichomes, similar to those found on the dorsal surface (Fig. 1B). The dorsal surface of this mouthpart in the soldiers showed a 

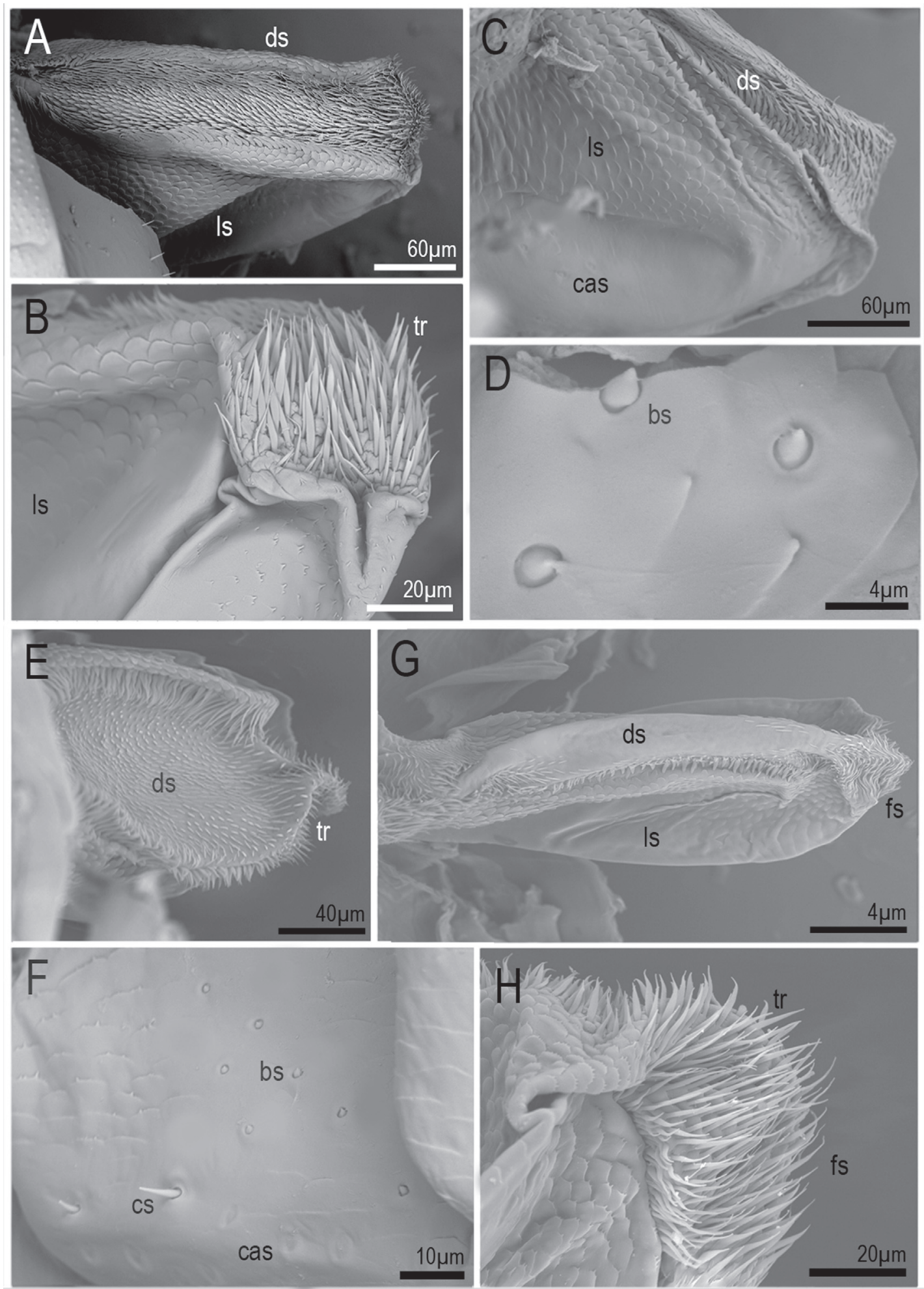

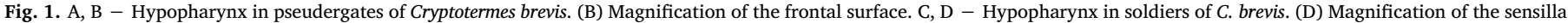

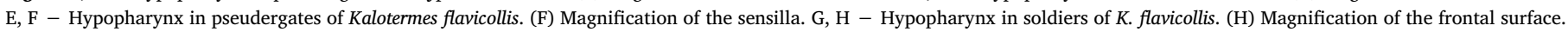
$\mathrm{bs}=$ basiconica sensilla; cas = campaniformia sensilla; cs = chaetica sensilla; ds = dorsal surface; fs $=$ frontal surface; ls = lateral surface; tr $=$ trichomes

similar trichome arrangement as in the pseudergates, with long, thick, and unidirectional trichomes (Fig. 1C); the same occurred with the frontal surface. Furthermore, basiconica and campaniformia sensilla were observed on the lateral surface, more precisely in a protuberance near the basal region of the hypopharynx in pseudergates and soldiers (Fig. 1D).

\subsection{Kalotermes flavicollis (Kalotermitidae)}

In the pseudergates, the dorsal surface of the hypopharynx was covered with sparse, thick, and short trichomes. These structures were directed towards the posterior region and varied in length. As described in the pseudergates of C. brevis, two stripes of long, thick trichomes defined the dorsal surface of the hypopharynx, followed by scale 

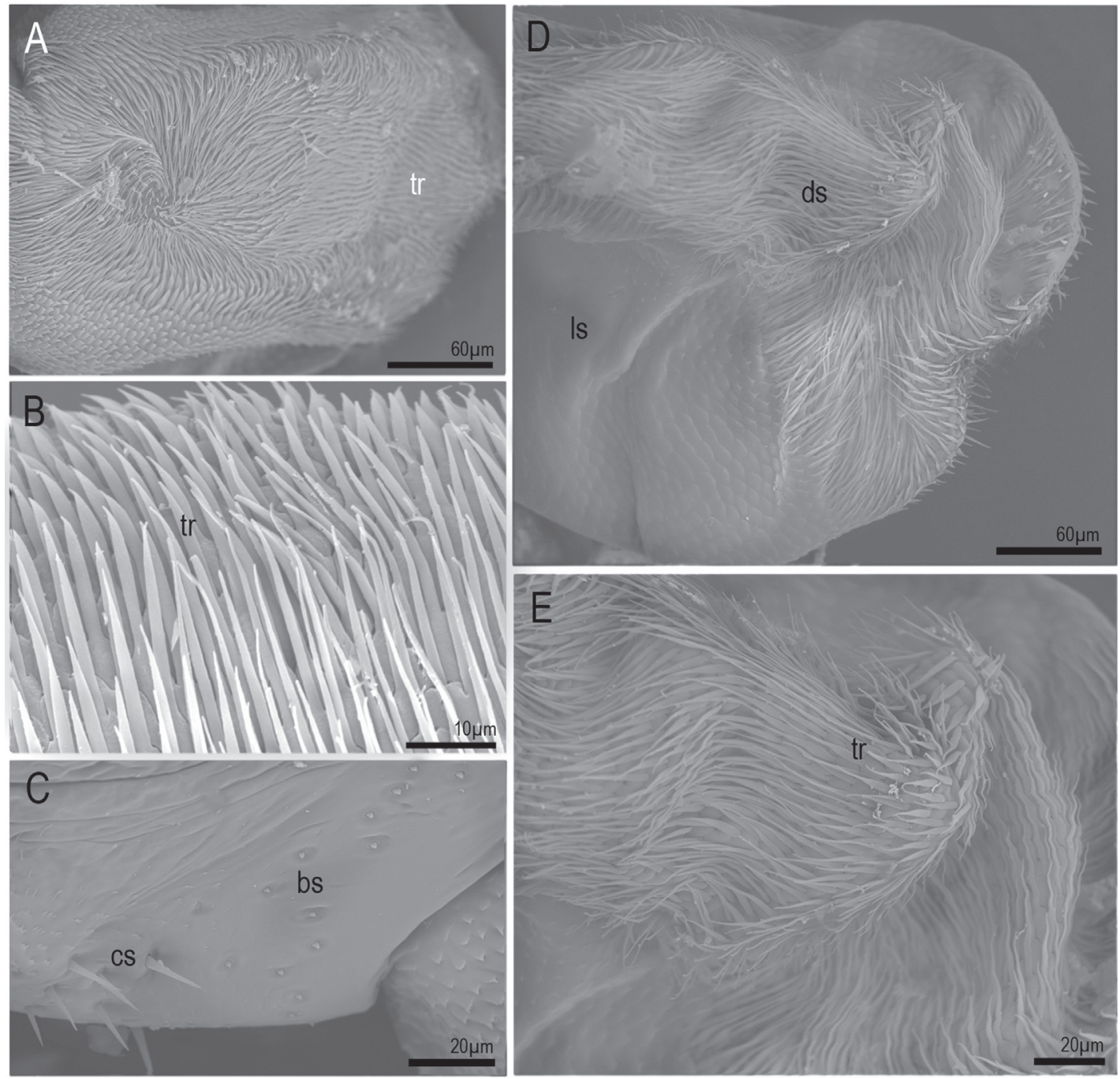

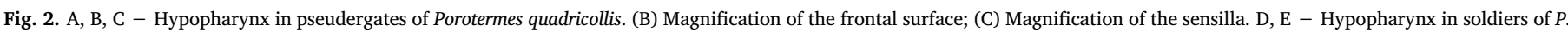
quadricollis. (E) Magnification of the dorsal surface. bs = basiconica sensilla; $\mathrm{cs}=$ chaetica sensilla; ds $=$ dorsal surface; ls $=$ lateral surface; tr $=$ trichomes.

ornamentations of the cuticle (Fig. 1E). The frontal region also featured a small quantity of trichomes (Fig. 1F). The dorsal surface of the hypopharynx in soldiers was mostly smooth, exhibiting few short, thin trichomes. This region also was delimited by two stripes of trichomes and followed by the lateral cuticle (Fig. 1G). The frontal region displayed a small, forward-facing arrangement of thick and long trichomes (Fig. 1H). There were also three types of sensilla: basiconica, chaetica, and campaniformia, located on a lateral protuberance of the hypopharynx in the pseudergates and soldiers, close to the basal portion.

\subsection{Porotermes quadricollis (Stolotermitidae)}

The pseudergates showed a large quantity of thick and long trichomes on the dorsal surface of the hypopharynx, and these structures were arranged unidirectionally towards the posterior region (Fig. 2A). Thick and long trichomes formed a unidirectional arrangement on the frontal surface of the hypopharynx, as observed in the pseudergates of C. brevis (Fig. 2B). In the lateral region of the hypopharynx in the pseudergates, basiconica and chaetica sensilla were observed, the former in larger quantities (Fig. 2C). The dorsal surface of the hypopharynx in soldiers of $P$. quadricollis exhibited the same morphological pattern described for $C$. brevis. This region was flanked by two stripes of thick trichomes and by the lateral surface, which contains cuticle with scale ornamentations (Fig. 2D and E).

\subsection{Serritermes serrifer (Serritermitidae)}

The trichomes observed on the dorsal surface of the hypopharynx in pseudergates were long and thin and did not cover the posterior region of this surface. Two stripes of thick and long trichomes flanked the dorsal part of the hypopharynx, and were followed by scale ornamentations of the cuticle on the lateral surface (Fig. 3A). The frontal surface displayed a large amount of long, thin trichomes, unlike the other OP species (Fig. 3B and C). The dorsal surface of the hypopharynx in the soldiers was mostly smooth, with few arrangements of long, thin trichomes. Two stripes of thick trichomes were also observed along with the lateral cuticle (Fig. 3D and E). Basiconica and chaetica sensilla were observed on the lateral surface of the hypopharynx in the pseudergates (Fig. 3F) and soldiers (Fig. 3G).

\subsection{Mastotermes darwiniensis (Mastotermitidae)}

The dorsal surface of the hypopharynx was surrounded by two stripes of thick trichomes which limited a central area where trichomes were lacking. The frontal region, however, was covered with a substantial quantity of long, thin trichomes. In the soldiers, the dorsal region of the hypopharynx was mostly smooth with few arrangements of short, thin trichomes. Two stripes of trichomes flanked the dorsal surface, following the same pattern observed in the other termites. Unlike 

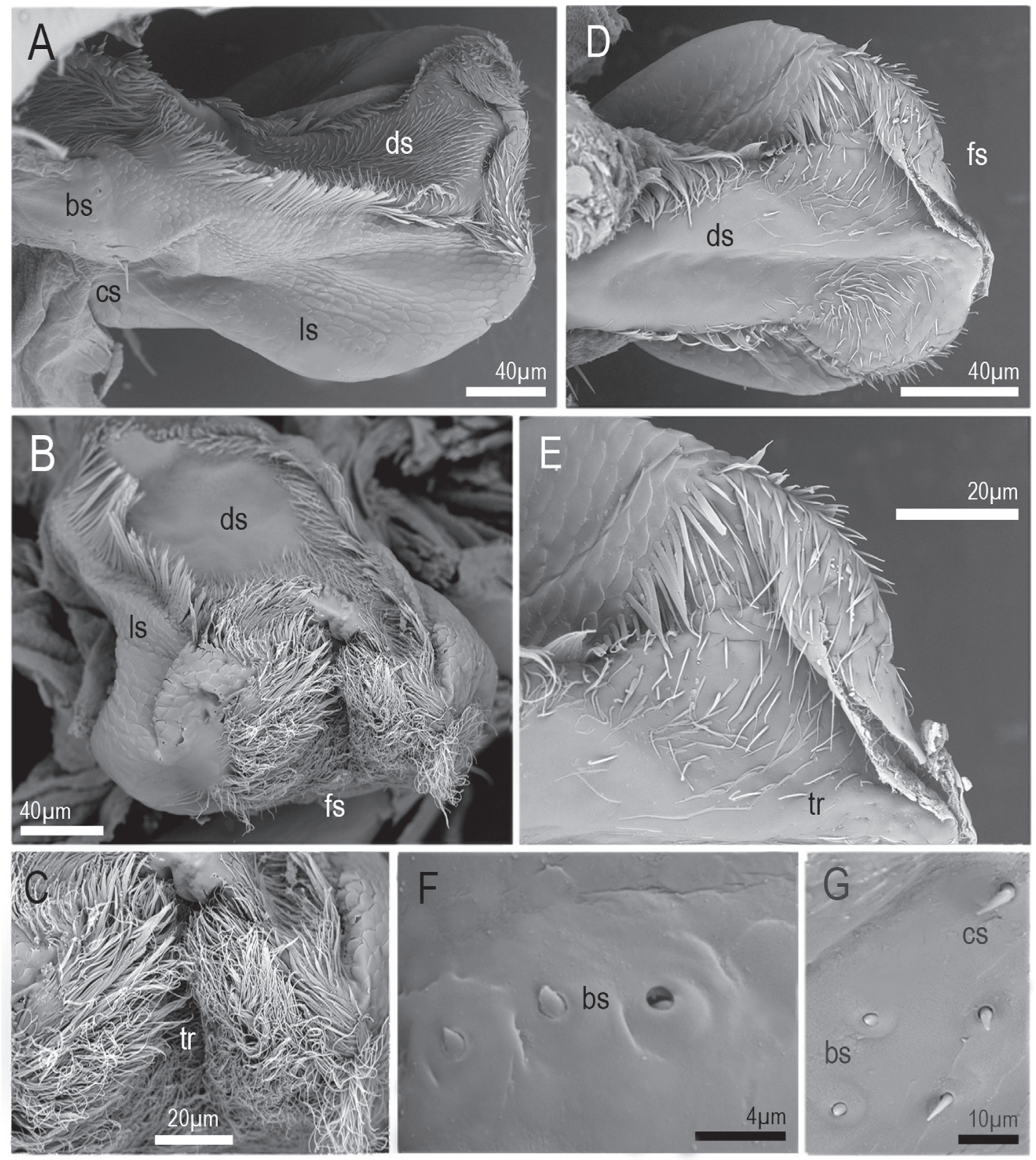

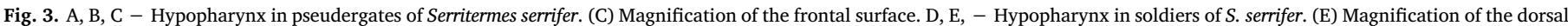

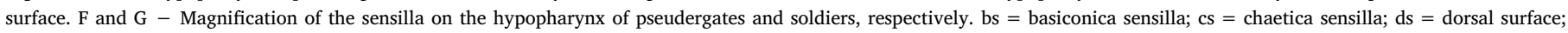
$\mathrm{fs}=$ frontal surface; ls = lateral surface; $\mathrm{tr}=$ trichomes.

the workers, in the soldiers the frontal region of the hypopharynx contained a few short, thin trichomes. Arrangements of basiconica and chaetica sensilla were observed on the hypopharynx of workers and soldiers.

\subsection{Coptotermes gestroi (Rhinotermitidae)}

The worker hypopharynx showed a small quantity of thin trichomes on the dorsal surface. Most part of this region was smooth and surrounded laterally by two stripes of thick trichomes (Fig. 4A). The cuticle of the lateral surface of the hypopharynx featured scale ornamentation flanking the stripes, and the frontal surface demonstrated a dense arrangement of long, thin trichomes (Fig. 4B). In the soldiers, the dorsal region was smooth and the frontal surface did not contain an expressive amount of trichomes (Fig. 4C and D). The lateral protuberances exhibited basiconica, chaetica (Fig. 4E), and campaniformia sensilla.

\subsection{Heterotermes tenuis (Rhinotermitidae)}

The workers displayed similar characteristics to those of C. gestroi, with small quantities of trichomes and a large smooth area of the dorsal surface ( $4 \mathrm{~F}$ and $\mathrm{G}$ ). An expressive quantity of these structures was seen on the frontal surface. The soldiers also exhibited similar hypopharynx morphology to that of $C$. gestroi soldiers, without significant quantities of trichomes on the dorsal and frontal surfaces of the hypopharynx (Figs. 4H and I).

\subsection{Syntermes grandis (Termitidae: Syntermitinae)}

The dorsal surface of the hypopharynx in dark-head workers was predominantly smooth, while a few parts were covered with short, thin trichomes. The dorsal surface of the hypopharynx in white-head workers also followed this pattern. The frontal region in dark-head workers contained a large amount of long, thin trichomes arranged in a 

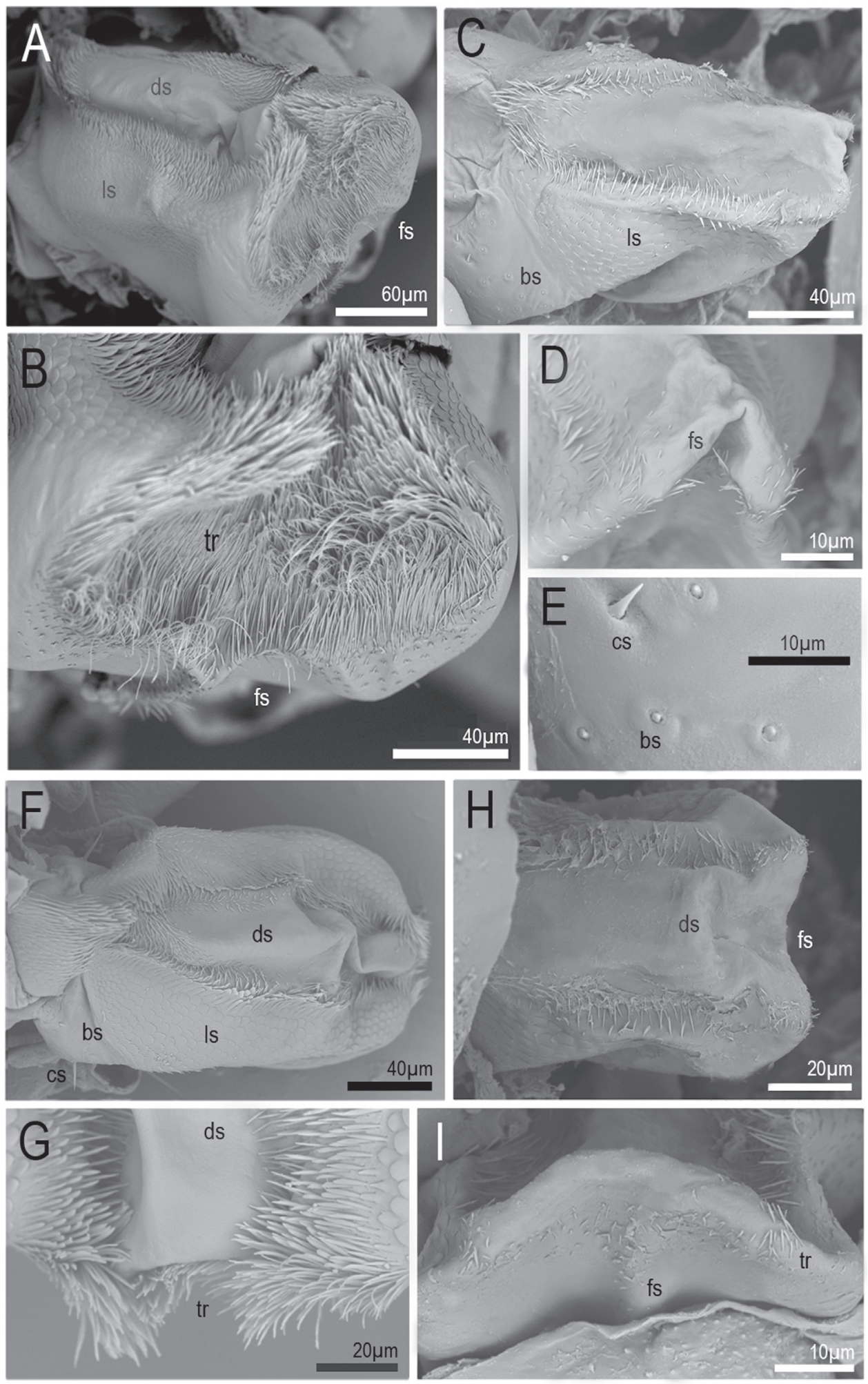

Fig. 4. A, B - Hypopharynx in workers of Coptotermes gestroi. (B) Magnification of the frontal surface. C, D, E - Hypopharynx in soldiers of $C$. gestroi. (C) Magnification of the frontal surface; (E) Magnification of the sensilla. F, G - Hypopharynx in workers of Heterotermes tenuis. (G) Magnification of the dorsal surface. H, I - Hypopharynx in soldiers of H. tenuis. (I) Magnification of the frontal surface. bs = basiconica sensilla; cs = chaetica sensilla; $\mathrm{ds}=$ dorsal surface; $\mathrm{fs}=$ frontal surface; ls = lateral surface; $\operatorname{tr}=$ trichomes. forward direction (Fig. 5A and B). These same structures were observed in white-head workers (Fig. 5C and D). The dorsal surface of the soldier hypopharynx was also smooth, presenting few arrangements of short, thin trichomes. The frontal surface was smooth and did not contain a substantial quantity of trichomes (Fig. 5E). All three types of sensilla were observed in all the castes; Fig. 5F and G show basiconica sensilla.

\subsection{Cornitermes cumulans (Termitidae: Syntermitinae)}

The dorsal surface of the worker hypopharynx contained few short, thin trichomes, similar to $S$. grandis workers, followed by thick trichomes flanking the dorsal surface (Fig. 5H). The frontal region exhibited a large amount of long, thin trichomes facing forward (Fig. 5I). 

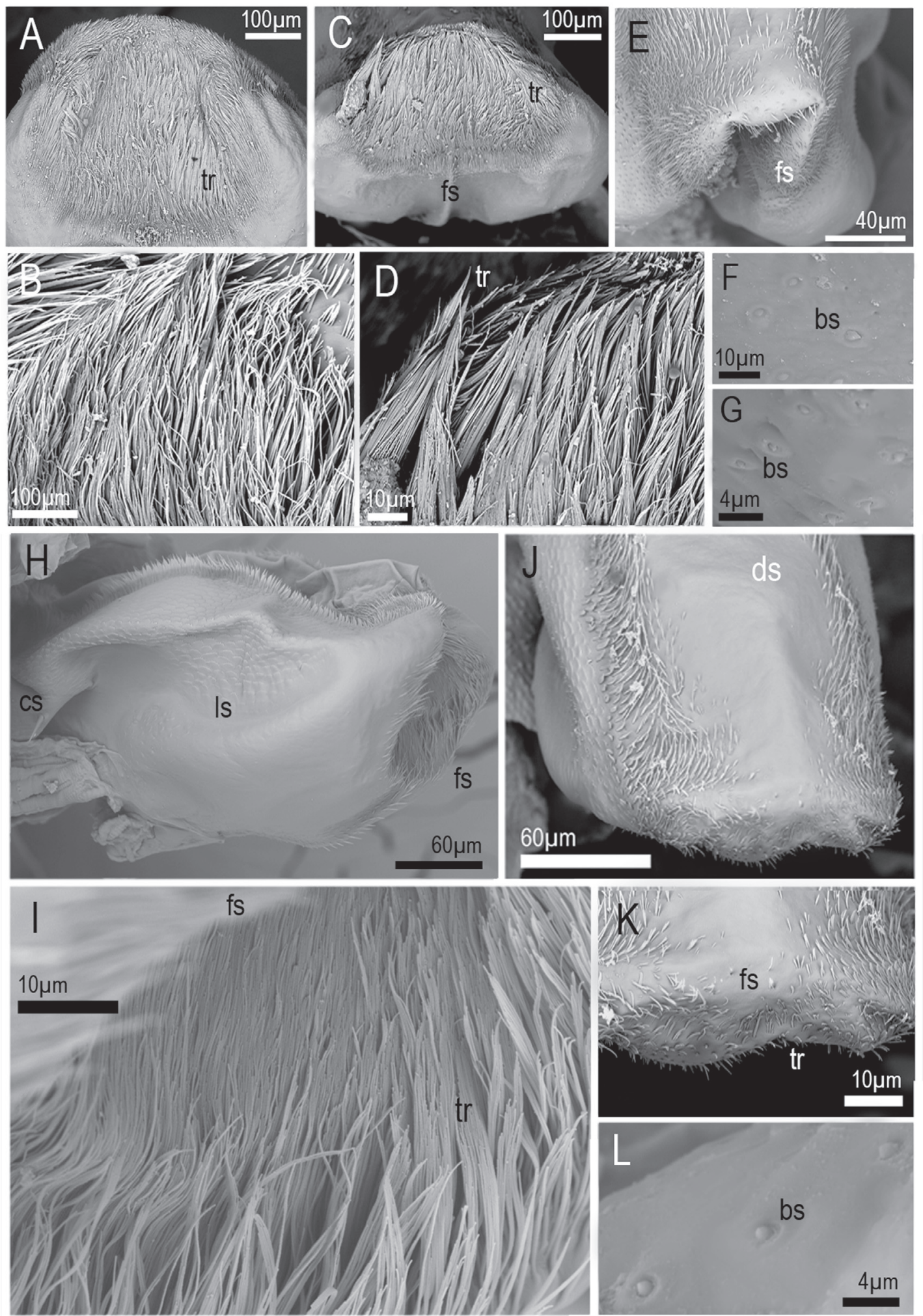

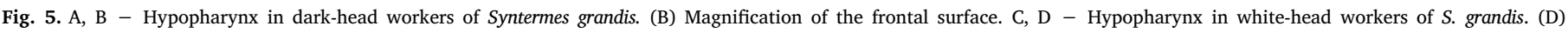

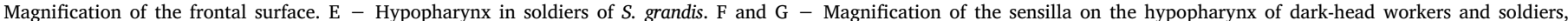

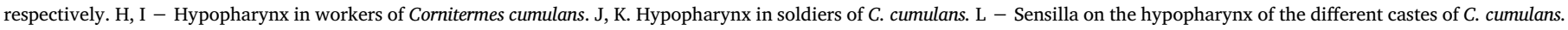
bs = basiconica sensilla; $d s=$ dorsal surface; $\mathrm{fs}=$ frontal surface; $1 \mathrm{~s}=$ lateral surface; $\mathrm{tr}=$ trichomes.

In soldiers, the dorsal surface contained few trichomes and a large, smooth region (Fig. 5J) flanked by two stripes of short, thin trichomes. The frontal surface followed the pattern observed in soldiers of $S$. grandis (Fig. 5K). Sensilla were also observed on the protuberances of the lateral surface of the hypopharynx in both castes (Fig. 5L).

\subsection{Nasutitermes aquilinus (Termitidae: Nasutitermitinae)}

The frontal surface of the hypopharynx in the major workers was covered with long, thin trichomes in a unidirectional arrangement (Fig. 6A). The dorsal surface was mostly smooth, and a few short, thin 

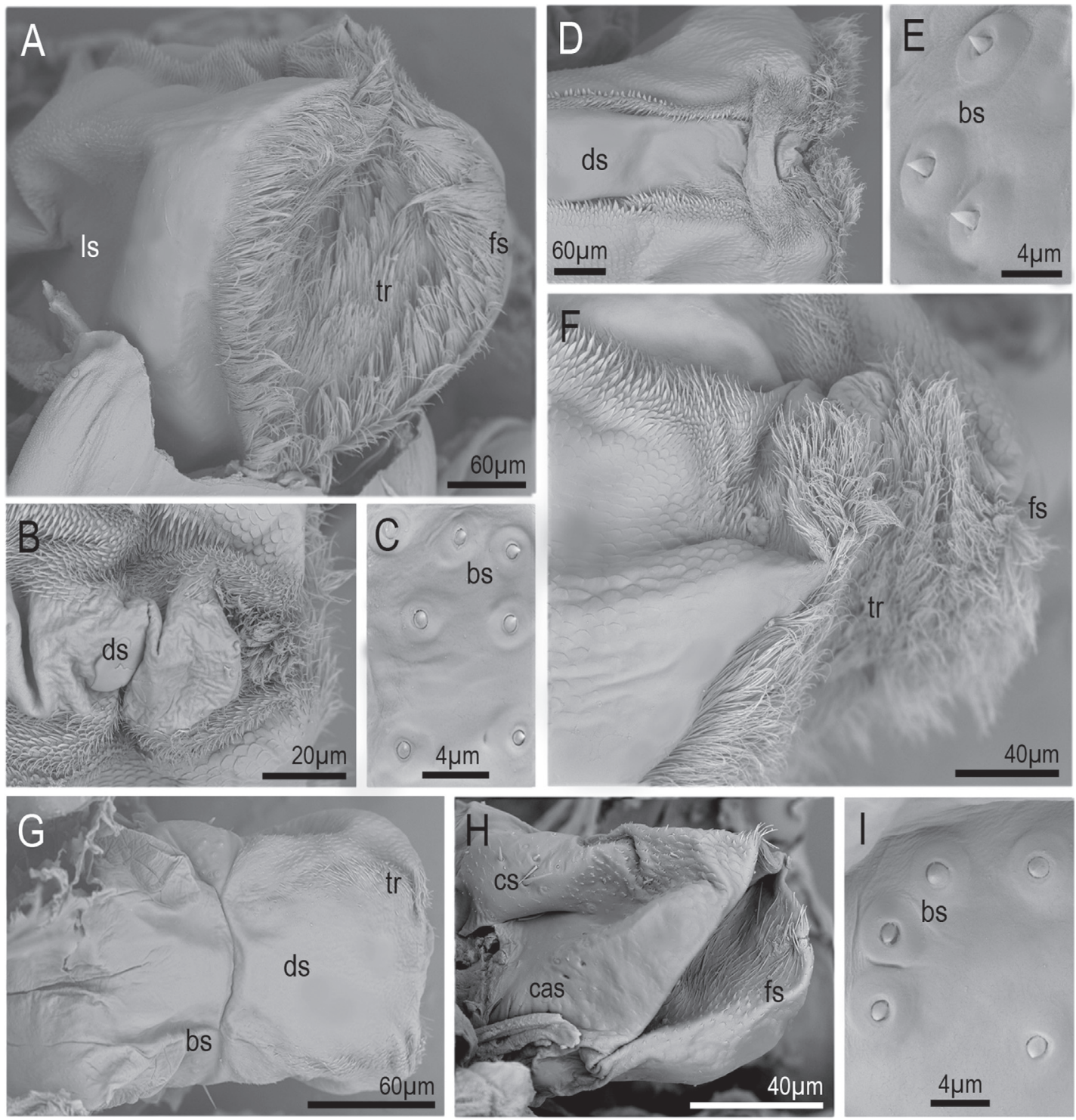

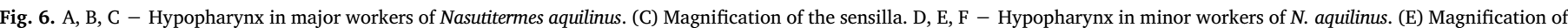

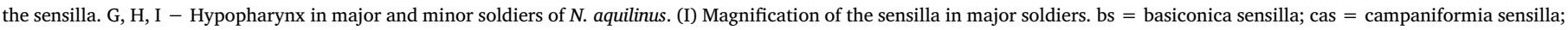
cs = chaetica sensilla; $\mathrm{ds}=$ dorsal surface; $\mathrm{fs}=$ frontal surface; ls = lateral surface; $\mathrm{tr}=$ trichomes.

trichomes were observed near the two stripes of thick trichomes flanking the dorsal surface (Fig. 6B). Basiconica sensilla were observed on the protuberances of the lateral surface (Fig. 6C). In the minor workers, the dorsal and frontal surfaces of the hypopharynx followed the pattern observed in the major workers (Fig. 6D and F) and basiconica sensilla were also observed on the lateral surface (Fig. 6E). In both major and minor soldiers, the dorsal surface of the hypopharynx was devoid of trichomes, but was flanked by two stripes of trichomes and scale ornamentations of the cuticle (Fig. 6G). A few short, thin trichomes were observed on the frontal surface, but most of this surface was smooth (Fig. 6H). Basiconica, chaetica, and campaniformia sensilla were observed on the protuberance of the lateral surface of the hypopharynx in both types of soldiers (Fig. 6I).

\subsection{Ruptitermes reconditus (Termitidae: Apicotermitinae)}

In the workers, the dorsal surface of the hypopharynx contained few short, thin trichomes. Most of this region was smooth and exhibited tiling ornamentations (Fig. 7A and B). Two stripes of thick trichomes were arranged around the dorsal surface, and the cuticle featured scale ornamentations in the lateral surface. The frontal surface of the hypopharynx contained a large quantity of long, thin trichomes in a unidirectional arrangement (Fig. 7C). Groupings of sensilla were observed on the lateral protuberances and the campaniformia sensilla were detailed in an arrangement which was involved by the cuticle ornamentations (Fig. 7D).

\subsection{Ruptitermes pitan (Termitidae: Apicotermitinae)}

The dorsal surface of the hypopharynx showed morphology similar to that observed in $R$. reconditus. The smooth portion also showed tiling ornamentations (Figs. 7E and F). The frontal surface was covered with long, thin trichomes (Fig. 7G) and sensilla were also observed on the lateral protuberances near the base of the hypopharynx (Fig. 7H).

\subsection{Ruptitermes xanthochiton (Termitidae: Apicotermitinae)}

In the workers, the dorsal surface of the hypopharynx contains small 

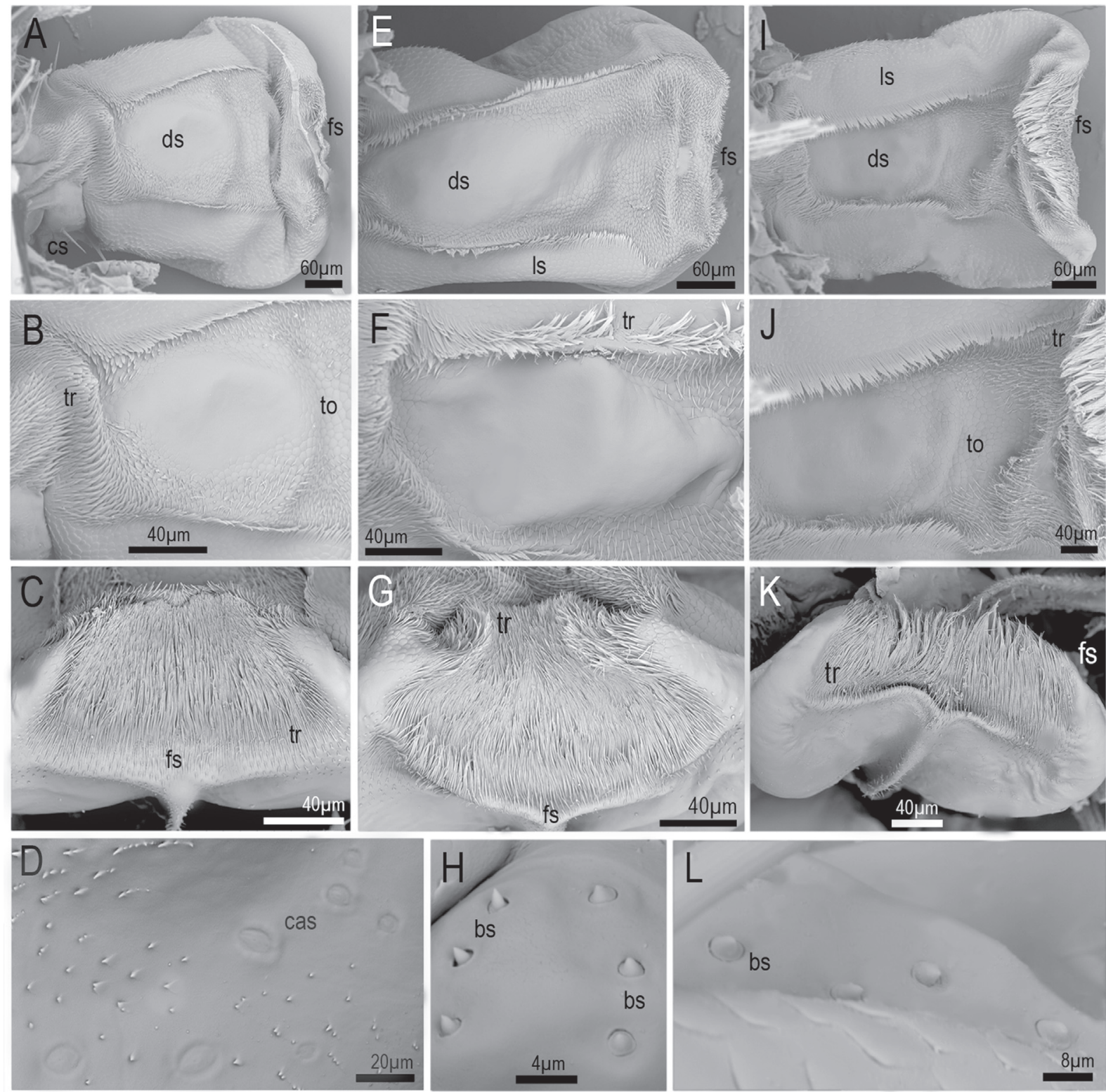

bs

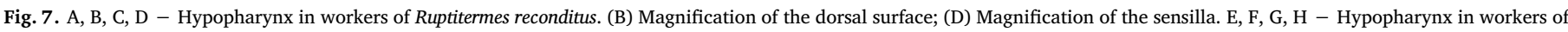

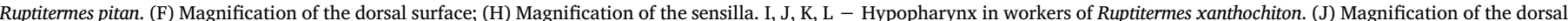

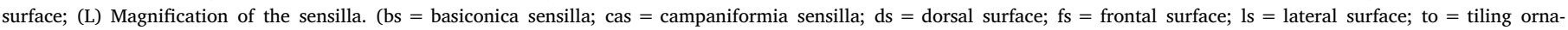
mentations; $\operatorname{tr}=$ trichomes.

quantities of thin trichomes, similar to the other Ruptitermes spp. described above (Fig. 7I and J). The tiling ornamentation on the dorsal surface of the hypopharynx also occurred in this species. On the frontal surface, long, thin trichomes were arranged densely in a unidirectional manner (Fig. 7K). The arrangement of the sensilla was also observed on the lateral surface of the hypopharynx and the basiconica sensilla were detailed (Fig. 7L).

\section{Discussion}

According to the results, there were differences in the location, quantity and morphology of the trichomes in the hypopharynx of OP and MP termites. Scanning microscopy of the mouthpart morphology has been well documented in different insect orders, especially Coleoptera (Jałoszyński and Beutel, 2012; Karolyi et al., 2016), Lepidoptera (Lehnert et al., 2016), Orthoptera (Krenn et al., 2016; Hsiao et al., 2017) and Mecoptera (Huang and Hua, 2011). Nevertheless, little information about the morphological features of the termite hypopharynx is available hitherto.

The arrangement of trichomes in OP termites differed from that of MP termites because the former group presented few trichomes in the frontal region of the hypopharynx, with exception of $S$. serrifer, which had a hypopharynx very similar to that of MP group. This may be result of the inclusion of this species as an OP termite, since $S$. serrifer is an obligatory inquiline found inside Cornitermes spp. nests (Constantino, 2015). According to the same author, S. serrifer feeds on vegetal material stored in the host nest walls. Although this species does not live inside wood, its life cycle and some ecological characteristics are similar to those observed in the other OP termites, as $S$. serrifer never forages outside the host nest and lacks a true worker caste (Barbosa and Constantino, 2017).

The species $P$. quadricollis presented a unique distribution of dense trichomes, unlike those observed in $K$. flavicollis but similar to those found in the hypopharynx of $C$. brevis. The hypopharynx of the termite 
Zootermopsis sp. was studied by Rudolph et al. (1990), but these authors only verified the presence of trichomes on the hypopharynx and did not present more details about the morphology of this mouthpart. These same authors proposed that pseudergates of Kalotermitidae exhibited a small quantity of trichomes on the frontal region of the hypopharynx, similar to the results obtained in the present study.

All the MP termites had very similar hypopharynxes within the caste, but expressive differences were seen between the workers and soldiers (Table 1). The morphology of the hypopharynx in the MP termites analyzed in this present study corresponds with the ecological habits of these insects, which forage outside the nest to explore water and food sources. The trichome arrangements on the frontal region of this mouthpiece indicated that both major and minor workers of $N$. aquilinus may be able to intake water from the soil. The same arrangement was observed in Cornitermes cumulans and Syntermes grandis. The hypopharynx morphology observed in $M$. darwiniensis also reflects the ecological habits of this species, which even being a basal representative of Isoptera, has large colonies and exploits multiple external resources (Korb and Thorne, 2017).

The trichome arrangement on the hypopharynx of $C$. gestroi and $H$. tenuis, both representatives of the family Rhinotermitidae, reinforced the characteristics of MP termites, since these species build galleries to exploit different resources outside the nest (Arab and Costa-Leonardo, 2005). These species present economic interest in some locations and water deprivation may be an important strategy in avoiding infestations by these insects, since the presence of moisture around structures may attract these termite species (Rudolph et al., 1990). Workers of Ruptitermes spp. showed similar hypopharynx morphology, with many trichomes present on the frontal surface. These species are subterranean and forage outside the nest (Costa-Leonardo, 2004), therefore the trichome arrangements may improve their water acquisition.

In soldiers of all MP termites, few trichomes were found on the hypopharynx, and are mostly located in the frontal region; this portion is used in water intake, suggesting that termites of this caste are not able to drink water by themselves. According to Sieber and Kokwaro (1982), only workers of Macrotermes michaelseni were observed drinking water with the hypopharynx protruded toward a moist source after $15 \mathrm{~h}$ of water deprivation. Soldiers of C. gestroi and C. cumulans were kept under hydric stress conditions for $16 \mathrm{~h}$, and subsequently were not observed drinking water when it was offered. However, these soldiers were observed performing trophallaxis with workers of the same species (Silva and Costa-Leonardo, unpublished results). These observations reinforce that soldiers are dependent on trophallaxis to increase the water and food consumption because the morphological modifications of their mandibles for defense prevents them from feeding by themselves (Cabrera and Rust, 1999; Suárez and Thorne, 2000; Huang et al., 2008).

The functional morphology of the hypopharynx has been neglected, although termites use it to intake water from the soil and for reposition soil particles during tunnel excavation (Rudolph et al., 1990; Li and Su, 2009). Still, according to Rudolph et al. (1990), the arrangement of the trichomes on the surface of the hypopharynx exerts capillary forces which extract water from the soil, and constitutes an important tool for hydric dynamics in termites.

In Isoptera, sensorial receptors have already been described in antennae, cercus, frontal tubel of soldiers and gland openings (CostaLeonardo and Soares, 1997; Costa-Leonardo, 2006; Santos and CostaLeonardo, 2006; Costa-Leonardo and Haifig, 2014). Although these receptors have been described in different mouthparts, as labial and maxillary palps (Costa-Leonardo and Haifig, 2014), clarification of the presence, type, and distribution of sensilla in the termite hypopharynx had been lacking.

The presence of chemo-and mechanoreceptors in mouthparts is important for insect physiology and this is the first detailed record of these structures in termite hypopharynx. In our study, the lateral surface of hypopharynx always presented the same three types of sensilla in all the castes and species analyzed and, probably, the presence of these sensilla in this hypopharynx region may facilitate the environmental perception during water intake and tunnel excavation (Rudolph et al., 1990; Li and Su, 2009). The hypopharynx sensilla vary in location and number among insect groups and instars (Chapman, 1982; Chapman et al., 2013), although there are also records of their absence, as observed in the horsefly Tabanus nigrovittatus (Stoffolano and Yin, 1983) and in the European sunflower moth Homoeosoma nebulella (Faucheux, 1995).

The quantity and location of trichomes on the hypopharynx varied among termite species, and these characteristics, reinforced by feeding and nesting preferences, may classify them as OP or MP type termites, with the exception of $S$. serrifer. Additionally, the morphology of the hypopharynx was an important indicator of physiological differences among the castes reinforcing the dependence of the trophallaxis process by soldiers.

\section{Acknowledgements}

The authors would like to thank the financial support from Conselho Nacional de Desenvolvimento Científico e Tecnológico- $\mathrm{CNPq}$ (Processes 305539/2014-0 and 404801/2015-3).

\section{References}

Arab, A., Costa-Leonardo, A.M., 2005. Effect of biotic and abiotic factors on the tunneling behavior of Coptotermes gestroi and Heterotermes tenuis (Isoptera: Rhinotermitidae). Behav. Process. 70 (1), 32-40. http://dx.doi.org/10.1016/j.beproc.2005.04.001.

Barbosa, J.R.C., Constantino, R., 2017. Polymorphism in the neotropical termite Serritermes serrifer. Entomol. Exp. Appl. 163 (1), 43-50.

Buder, G., Klass, K.D., 2013. A comparative study of the hypopharynx in Dictyoptera (Insecta). Zoologischer Anzeiger - J. Comp. Zool. 252 (3), 383-403. http://dx.doi. org/10.1016/j.jcz.2012.10.004.

Cabrera, B.J., Rust, M.K., 1999. Caste differences in feeding and trophallaxis in the western drywood termite, Incisitermes minor (Hagen) (Isoptera, Kalotermitidae). Insectes Soc. 46 (3), 244-249.

The Insects: Structure and Function. In: Chapman, R.F., Simpson, S.J., Douglas, A.E (Eds.), 5th ed. Cambridge University Press, New York.

Chapman, R.F., 1982. Chemoreception: the significance of receptor numbers. Adv. Insect Physiol. 16, 247-356.

Constantino, R., 2015. Cupins do Cerrado, 1st ed. Technical Books, Rio de Janeiro.

Costa-Leonardo, A.M., Haifig, I., 2014. Termite communication during different behavioral activities. In: In: Witzany, G. (Ed.), Biocommunication of Animals vo1. 10. Springer, Netherlands, pp. 161-190. http://dx.doi.org/10.1007/978-94-007-7414810.

Costa-Leonardo, A.M., Soares, H.X., 1997. Morphological aspects of neotropical termite antenna under scanning microscopy. Revista Brasileira de Entomologia 41 (1), 47-52.

Costa-Leonardo, A.M., 2004. A new interpretation of the defense glands of neotropical Ruptitermes (Isoptera, Termitidae, Apicotermitinae). Sociobiology 44 (2), 1-12.

Costa-Leonardo, A.M., 2006. Morphology of the sternal gland in workers of Coptotermes gestroi (Isoptera, Rhinotermitidae). Micron 37 (6), 551-556. http://dx.doi.org/10. 1016/j.micron.2005.12.006.

Faucheux, M.J., 1995. Sensilla on the larval antennae and mouthparts of the european sunflower moth, Homoeosoma nebulella Den. and Schiff. (Lepidoptera: Pyralidae). Int. J. Insect Morphol. Embryol. 24 (4), 391-403. http://dx.doi.org/10.1016/00207322(95)00011-R.

Grube, S., Rudolph, D., 1995. Termites in arid environments: the water balance of Psammotermes allocerus Silvestri. Mitt. Dtsch. Ges. Allg. Angew. Entomol. 10, 665-668.

Hsiao, T.F., Yang, J.T., Chen, M.Y., 2017. Grasshopper mandibles functional morphology adaptation to food plants (Orthoptera: Caelifera) from the subtropical forest ecosystem, central Taiwan. Adv. Entomol. 5, 40-53. http://dx.doi.org/10.4236/ae.2017. 51004.

Huang, J., Hua, B., 2011. Functional morphology of the mouthparts in the scorpionfly Sinopanorpa tincta (Mecoptera: Panorpidae). Micron 42 (5), 498-505. http://dx.doi. org/10.1016/j.micron.2011.01.011.

Huang, Q.Y., Wang, W.P., Mo, R.Y., Lei, C.L., 2008. Studies on feeding and trophallaxis in the subterranean termite Odontotermes formosanus using rubidium chloride. Entomol. Exp. Appl. 129 (2), 210-215.

Jałoszyński, P., Beutel, R.G., 2012. Functional morphology and evolution of specialized mouthparts of Cephenniini (Insecta, Coleoptera, Staphylinidae, Scydmaeninae). Arthropod Struct. Dev. 41 (6), 593-607. http://dx.doi.org/10.1016/j.asd.2012.07. 002.

Karolyi, F., Hansal, T., Krenn, H.W., Colville, J.F., 2016. Comparative morphology of the mouthparts of the megadiverse South African monkey beetles (Scarabaeidae: Hopliini): feeding adaptations and guild structure. PeerJ 4, 1-22. http://dx.doi.org/ 10.7717/peerj.1597. 
Korb, J., Thorne, B.L., 2017. Sociality in termites. In: In: Rubenstein, D.R., Abbot, P. (Eds.), Comparative Social Evolution, vol. 1. Cambridge University Press, Cambridge, pp. 124-153.

Korb, J., 2008. The ecology of social evolution in termites. In: In: Korb, J., Heinze, J. (Eds.), Ecology of Social Evolution., vol. 7. Springer, Heidelberg, pp. 151-174.

Krenn, H.W., Fournel, J., Bauder, J.A.S., Hugel, S., 2016. Mouthparts and nectar feeding of the flower visiting cricket Glomeremus orchidophilus (Gryllacrididae). Arthropod Struct. Dev. 45 (3), 221-229.

Lehnert, M.S., Beard, C.E., Gerard, P.D., Kornev, K.G., Adler, P.H., 2016. Structure of the lepidopteran proboscis in relation to feeding guild. J. Morphol. 227 (2), 167-182.

Li, H.F., Su, N.Y., 2009. Buccal manipulation of sand particles during tunnel excavation of the Formosan subterranean termite (Isoptera: Rhinotermitidae). Ann. Entomol. Soc. Am. 102 (2), 333-338. http://dx.doi.org/10.1603/008.102.0216.

Lys, J., Leuthold, R., 1994. Forces affecting water imbibition in Macrotermes workers (Termitidae, Isoptera). Insectes Soc. 41 (1), 79-84. http://dx.doi.org/10.1007/ BF01240575.

Pearce, M.J., 1997. Termite biology and behaviour. In: Pearce, M.J. (Ed.), Termites: Biology and Pest Management. CAB International, Wallingford, United Kingdom, pp. $53-55$.

Rudolph, D., Glocke, B., Rathenow, S., 1990. On the role of different humidity parameters for the survival, distribution and ecology of various termite species. Sociobiology 17, 129-140.
Santos, C.A., Costa-Leonardo, A.M., 2006. Anatomy of the frontal gland and ultramorphology of the frontal tube in the soldier caste caste of species of Nasutitermitinae (Isoptera, Termitidae). Microsc. Res. Tech. 69 (11), 913-918. http://dx.doi.org/10.1002/jemt.2036.

Sieber, R., Kokwaro, E., 1982. Water intake by the termite Macrotermes michaelseni. Entomologia Experimentalis et Applicata 31, 147-153. http://dx.doi.org/10.1111/j. 1570-7458.1982.tb03126.x.

Sieber, R., Leuthold, R.H., 1981. Behavioural elements and their meaning in incipient laboratory colonies of the fungus-growing termite Macrotermes michaelseni (Isoptera: Macrotermitinae). Insectes Soc. 28 (4), 371-382. http://dx.doi.org/10.1007/ BF02224194.

Silveira-Neto, S., Nakano, O., Barbin, D., Vila-Nova, N., 1976. Manual de ecologia dos insetos. Editora Agronômica Cere, Piracicaba.

Snodgrass, R.E., 1993. Principles of Insect Morphology. Cornell University Press, New York.

Stoffolano Jr, J.G., Yin, L.R.S., 1983. Comparative study of the mouthparts and associated sensilla of adult male and female Tabanus nigrovittatus (Diptera: Tabanidae). J. Med. Entomol. 20 (1), 11-32.

Suárez, M., Thorne, B., 2000. Rate, amount and distribution pattern of alimentary fluid transfer via trophallaxis in three species of termites (Isoptera: Rhinotermitidae, Termopsidae). Ann. Entomol. Soc. Am. 93 (1), 145-155. http://dx.doi.org/10.1603/ 0013-8746(2000)093[0145:RAADPO]2.0.CO;2. 